\title{
The Self-Powered Detector Simulation 'MATiSSe' Toolbox applied to SPNDs for severe accident monitoring in PWRs
}

\author{
Loïc Barbot, Jean-François Villard, Stéphane Fourrez, Laurent Pichon and Hamid Makil.
}

\begin{abstract}
In the framework of the French National Research Agency program on nuclear safety and radioprotection, the 'DIstributed Sensing for COrium Monitoring and Safety' project aims at developing innovative instrumentation for corium monitoring in case of severe accident in a Pressurized Water nuclear Reactor. Among others, a new under-vessel instrumentation based on Self-Powered Neutron Detectors is developed using a numerical simulation toolbox, named 'MATiSSe'. The CEA Instrumentation Sensors and Dosimetry Lab developed MATiSSe since 2010 for Self-Powered Neutron Detectors material selection and geometry design, as well as for their respective partial neutron and gamma sensitivity calculations. MATiSSe is based on a comprehensive model of neutron and gamma interactions which take place in Selfpowered neutron detector components using the MCNP6 Monte Carlo code. As member of the project consortium, the THERMOCOAX SAS Company is currently manufacturing some instrumented pole prototypes to be tested in 2017 . The full severe accident monitoring equipment, including the standalone low current acquisition system, will be tested during a joined CEA-THERMOCOAX experimental campaign in some realistic irradiation conditions, in the Slovenian TRIGA Mark II research reactor.
\end{abstract}

Index Terms-Severe accident instrumentation, Corium monitoring, Self-powered neutron detectors, SPND, Monte Carlo codes, Pressurized water reactor, PWR.

\section{INTRODUCTION}

F OLLOWING the 2013 Fukushima accident, the French government launched an important research program on nuclear safety and radioprotection (RSNR), managed by the French National Research Agency (ANR). This strategic initiative is co-funded by the government and run by the General Commissariat of Investment (CGI) through the 'Investments for the Future' Program (PIA).

In this context, the DISCOMS project, which stands for 'DIstributed Sensing for COrium Monitoring and Safety',

Manuscript received April 19 $9^{\text {th }}$, 2017. This work was supported by the RSNR research program on nuclear safety and radioprotection managed by the French National Research Agency (ANR).

L. Barbot and J-F. Villard are with the CEA, DEN, DER, Instrumentation, Sensors and Dosimetry Laboratory, Cadarache, F-13108 St-Paul-LezDurance, France (e-mail: loic.barbot@cea.fr).

S. Fourrez and L. Pichon are with the THERMOCOAX SAS Company, BP26, F-61438 Flers Cedex, France (e-mail stephane.fourrez@thermocoax.com).

H. Makil is with the CEA, LIST, Sensors and Electronics Laboratory, Saclay, F-91191 Gif sur Yvette, France (e-mail: hamid.makil@cea.fr). contributes to develop new under-vessel instrumentation based on both distributed Optical Fiber Sensors and Self-Powered Neutron Detectors (SPNDs) [1].

SPNDs have been widely used in nuclear reactors as on-line IN-CORE neutron flux monitors since 1960 [2]. They are here considered to be part of an EX-CORE innovative instrumentation that would improve nuclear safety through corium monitoring in case of severe accident in Pressurized Water nuclear Reactors (PWR).

Two CEA laboratories (the Instrumentation Sensors and Dosimetry Lab - LDCI and the Sensors and Electronic Architecture Lab - LCAE) and the THERMOCOAX SAS Company co-developed a sensing instrumentation device including SPNDs and thermocouples as well as a standalone low current acquisition system. The paper details the capabilities of this device under mixed neutron and gamma irradiations, both in normal and severe accidental reactor operating conditions.

The LDCI's SPND simulation toolbox, named 'MATiSSe', standing for 'Monte cArlo Tool for SPND Simulation', is used to select SPND materials, to design geometries and to ensure that such detectors remain operational in any reactor situations. Full expected partial neutron and gamma sensitivities are calculated using the MATiSSe toolbox.

The THERMOCOAX SAS Company is currently manufacturing prototypes to be tested in 2017 in a European research reactor.

\section{OVERVIEW}

\section{A. Context}

The DISCOMS project intentions are to increase the safety both in existing and future Nuclear Power Plants, inquiring about the status of the third confinement barrier and defining possible mitigation strategies in case of severe accident. Nuclear instrumentation objectives are to detect reactor vessel breach and corium pouring on the concrete reactor pit basemat, to monitor the Molten Core Concrete Interaction, and to follow the corium location (up to the spreading compartment [core catcher] in the EPR) as well as the corium cooling kinetics [1]. 


\section{B. Instrumentation implantation}

SPNDs are considered within the DISCOMS project for their sensitivity to both neutrons and gamma. Such sensors will be deployed in the reactor core vicinity. Strategically processed, SPND signals will provide key information to the operators in any normal and severe accidental reactor conditions (GEN2\&3 PWRs). The sensor locations (see Figure 1) are essential as the severe accident monitoring mainly relies on neutron flux decreasing with the onset of the accident, and gamma flux increasing with the corium pouring (the temperature evolution being monitored with additional thermocouples) [1].

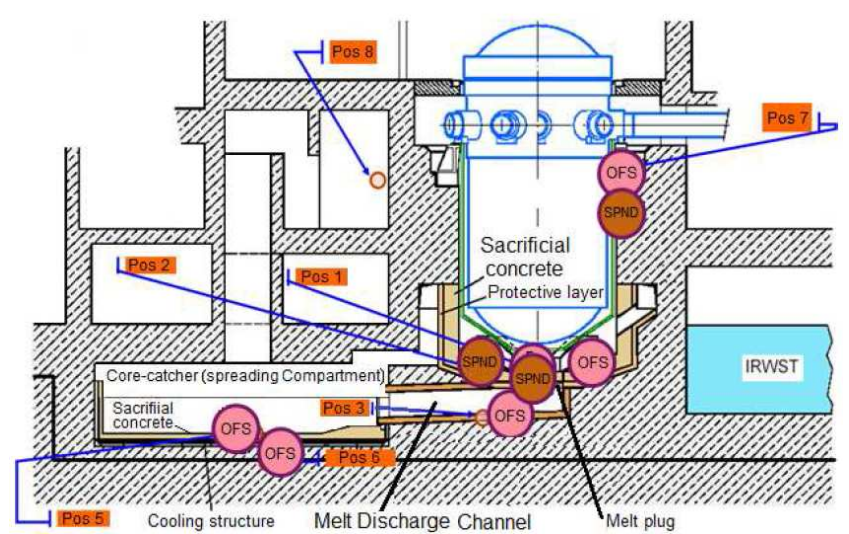

Figure 1: SPND and Optical Fiber Sensors locations for the DISCOMS project corium monitoring instrumentation [1].

GEN 2\&3 reactors' normal operations can be monitored with SPNDs located at reactor core mid height, where both neutron and gamma irradiation fields are at relatively high level. At this location, SPND signal is also providing important information at the beginning of the accident as the SPND current will drop drastically with the neutron flux.

To monitor accidental conditions (reactor vessel breach followed by the corium migration), sensors have to be deployed at the reactor vessel bottom. SPNDs could be placed either on the concrete basemat surface (GEN2 reactors) or embedded in the concrete sacrificial layer of the core melt stabilization system (GEN3 reactors). Radiation conditions on the basemat are changing from low level mixed field in normal situations up to high level pure gamma irradiation in accidental conditions.

Another challenge for the DISCOMS project concerns the direct wired connection from SPNDs and thermocouples to the monitoring equipment over a length of typically 200 meters including specifically designed and fully qualified watertight glass-metal connectors [3]. A standalone low current acquisition system is also currently developed with low energy consumption and reliable multichannel low current measurements (bottom limit $1 \mathrm{pA}$ ).

\section{Neutron and gamma flux calculations}

As part of the DISCOMS consortium, the Institute of Radiological Protection and Nuclear Safety (IRSN) and the
CEA Reactor Studies and Applied Mathematics Section (SERMA) were in charge of the radiation calculations in order to support the instrumentation implementation in GEN2\&3 reactors (normal and accidental conditions).

Particle transport simulations were performed using two Monte Carlo codes (MCNP6 [4] and TRIPOLI4 [5]), the JEFF3.1 [6] and ENDF-B/VII.1 [7] libraries and the Tihange-I (GEN2 - Belgium) and the EPR reactor models. GEN2 simulations results have been validated thanks to open experimental flux distribution data [8]. Only GEN2 data and results are presented in this paper.
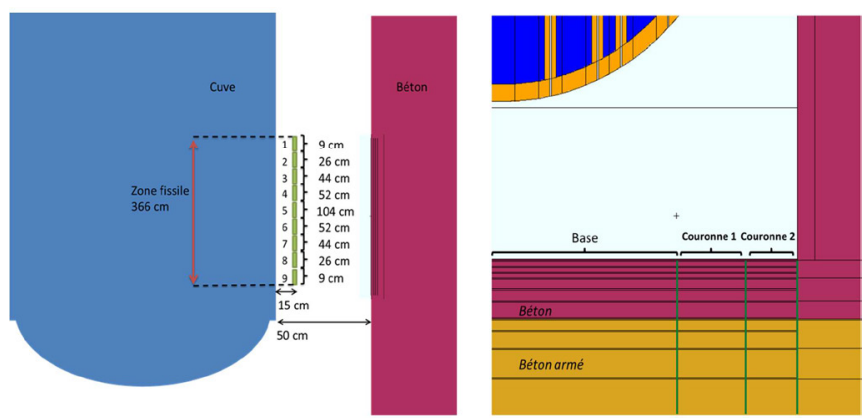

Figure 2: Monte Carlo calculation responses on the side and at the bottom of the vessel with respective segmentations [8].

For both normal and accidental conditions, neutrons and gamma spectra and flux level calculations were performed at SPND locations (see figures 2, 3 and 4). Those are used as entry data for the SPND simulation MATiSSe toolbox. The reactor core height has been divided in segments and the basement shared in a base and rings. The corium definition is approximated as a homogenous mixture of uranium and zirconium oxides and stainless steel. Radiation levels are estimated with a corium relocated on the reactor basemat three hours after the onset of the severe accident.

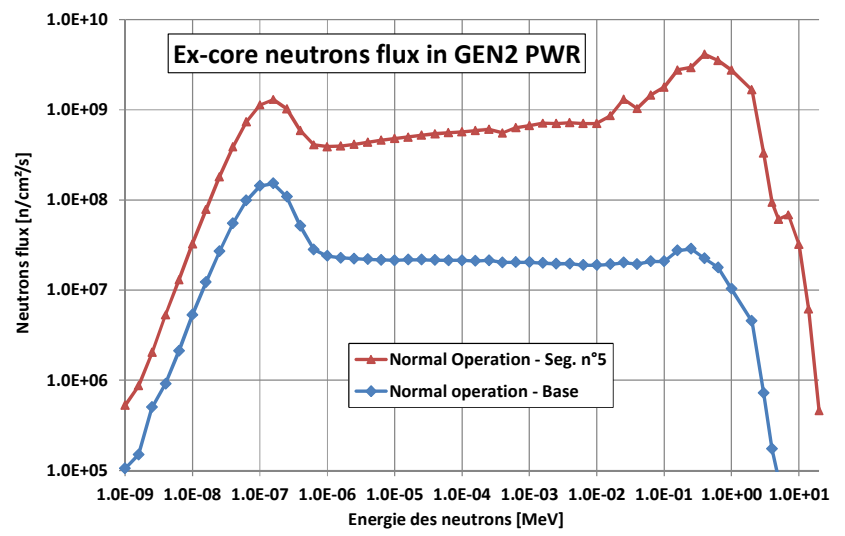

Figure 3: Neutron spectra in GEN2 PWR in Normal Operation; on the side of the vessel (Seg.5) and on the concrete basemat (Base). 


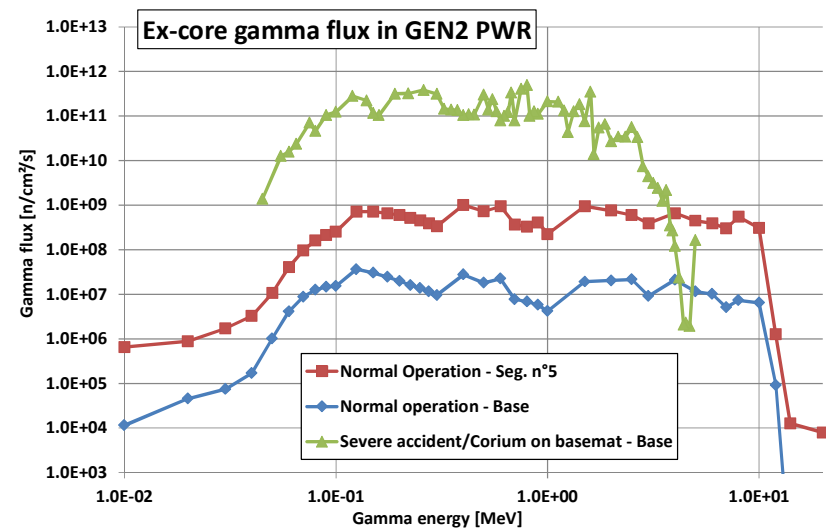

Figure 4: Gamma spectra in GEN2 PWR in Normal Operation (on the side of the vessel (Seg.5) and on the concrete basemat (Base)) and in case of Severe Accident (Corium on basemat - Base).

\section{SELF-POWERED DETECTOR SIMULATION}

The LDCI MATiSSe toolbox is based on a multistep Monte Carlo calculation model where SPNDs and their immediate environment are finely modelled (geometry and material definition). The SPND model originates from SCK $\cdot \mathrm{CEN}$ previous work [9] and has been constantly upgraded at CEA since 2010. The SPND response is predicted from thorough calculations of neutron and gamma partial detector sensitivities, using close neutron and gamma fields (levels and spectra) accurately established beforehand.

\section{A. The SPND Theory}

SPNDs are usually designed with a coaxial geometry with a central electrode (emitter) surrounded by an insulator and an external concentric electrode (sheath or collector) (see Figure 5). This sensitive part is connected to the measuring system by an integrated mineral insulated cable. The basic SPND operation principle is based on the collection of electrons created in the emitter, coming from neutron interactions with the detector materials. These moving electrons are generating a measurable direct current.

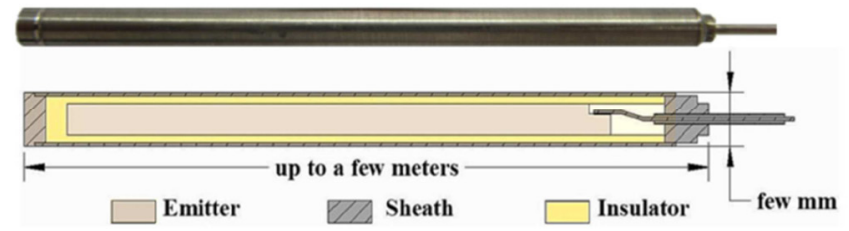

Figure 5: Sketch of a typical self-powered neutron detector

For neutron measurements, two types of SPNDs are considered. First, detectors with dominant $\left(n, \beta^{-}\right)$reaction are called 'delayed SPND' since their response time is driven by the decay constant of the created beta emitting isotopes. Second are 'prompt' detectors due to their instantaneous response to predominant $(\mathrm{n}, \gamma)(\gamma, \mathrm{e})$ reactions. External gamma interactions (fission, activation...) also create some free electrons in detectors denoted as $(\gamma, \mathrm{e})$ reactions. When the $(\gamma, e)$ reaction contribution is enhanced through specific material definition, the detector is called Self-Powered
Gamma Detector (SPGD) and is dedicated to gamma flux measurements [10].

While moving between the electrodes, created electrons are giving rise to a direct electric current between the emitter and the sheath, which is proportional to the mixed neutron and gamma field at the SPND location. When irradiated in a mixed field, the SPND total output current integrates partial currents coming from the three reactions mentioned above for each materials (emitter, insulator, sheath and close detector surroundings). These partial currents can be either positive or negative.

The mixed neutron-gamma sensitivity of all SPNDs is a key-point in the proposed severe accident monitoring strategy.

\section{B. The SPND Model}

The SPND model relies on two fundamental points: the exhaustive study of all possible free electron creation sources within SPND materials and the transport calculation of these different electrons (or beta particles) in the SPND components along with their respective charge depositions profiles. The SPND signal is determined as a combination of the net electron currents at the emitter/insulator and insulator/sheath boundaries. Moreover, under irradiation, electric charges deposited in the insulator are creating an electric field which alters electron paths. The fraction of electron currents reflected by the electric field is introduced in the SPND model as an analytical expression [9].

In SPNDs materials, 76 reactions $\left[\left(n, \beta^{-}\right),(n, \gamma)(\gamma, e)\right.$ and $(\gamma, e)][11]$ have been identified for their potential input to the total current. Only 19 reactions among them are considered to have a significant contribution to the measured signal [12]. Those reaction contributions are evaluated through multistep Monte Carlo calculations.

The 3 main contributions are calculated using neutron and gamma fields (levels and spectra) in the SPND vicinity, a fine model of the SPND and its immediate environment, different steps of Monte Carlo (MCNP6.1) and analytical calculations.

First step is performed using a shell neutron source positioned few millimeters outside the SPND. The neutron reaction rate level and the radial distribution of every $\beta^{-}$ emitter precursor $\left(\left(n, \beta^{-}\right)\right.$contribution) are estimated using the track length estimator of neutron flux (F4 Tally in MCNP6). The electron currents at every material boundary $((\mathrm{n}, \gamma)(\gamma, \mathrm{e})$ contribution) are calculated with the surface current estimator (F1 Tally in MCNP6) Secondly, ( $n, \beta^{-}$) contribution is determined through electron transport calculations using an electron source defined with a $\beta^{-}$radial distribution calculated previously for each $\beta^{-}$emitter. Thirdly, the $(\gamma, e)$ contribution is computed with a gamma source placed outside the SPND. In addition, the charge deposition is also calculated (+F8 Tally in MCNP6) for the three mentioned contributions.

At the end of the simulation process, the SPND total electric current is derived from the outward net electron currents at both emitter/insulant and insulant/sheath boundaries for all contributions and normalized toward the considered neutrons and gamma flux levels. It is then expressed in Amps. 
The multistep Monte Carlo calculations are now performed using the LDCI MATiSSe toolbox.

\section{The LDCI MATiSSe Toolbox}

The LDCI MATiSSe toolbox was developed to ease operator calculations for self-powered neutron detector design, simulation and operation. It runs the multistep SPND model in adequate order from a user SPND definition (see figure 6). The reaction contributions are evaluated through multistep Monte Carlo calculations using the MCNP6.1 code and the JEFF3.2 neutron data and the ENDF/B-VII.1 gamma data libraries. The JANIS4.0 web nuclear data application [13] provides the $\beta^{-}$energy spectra.

In the MATiSSe toolbox, each Monte Carlo and analytical calculation are coded separately in $\mathrm{C}++$ macros. The user defines both the SPND geometry and its close environment, and then launches calculations from a graphical user interface (GUI) developed with the Qt Creator 3.5.0 program (ICS Company).

Two different modes are available: 'automatic' one is running all steps automatically up to the final output current, and 'expert' mode is a step-by-step mode for advanced users.

At the end, the MATiSSe output is a direct electrical current comparable to the current generated in the SPND when irradiated in the same neutron and gamma conditions.

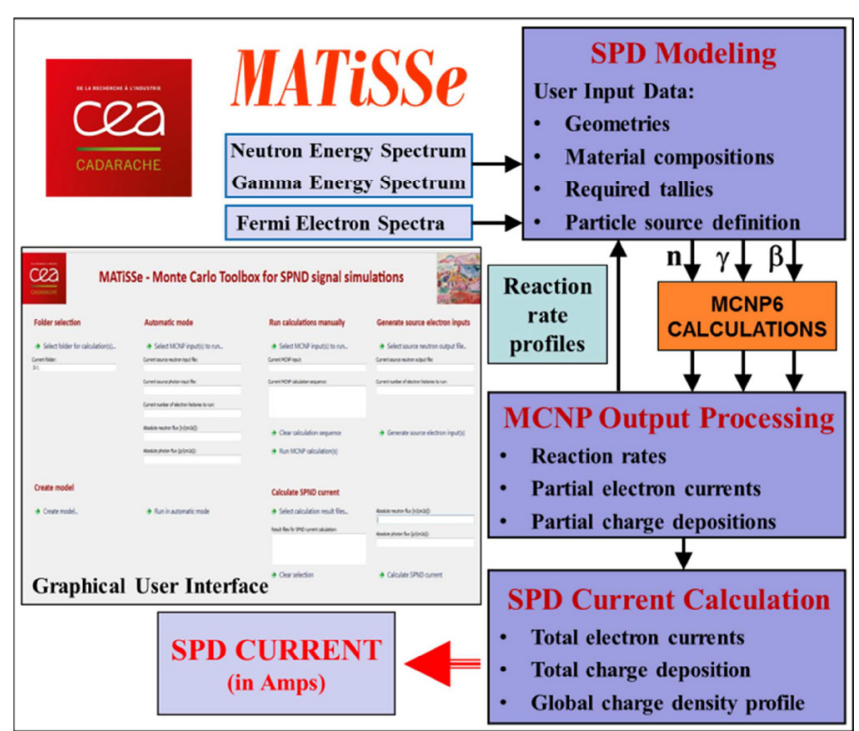

Figure 6: Block diagram of the LDCI MATiSSe toolbox for Self-Powered Neutron Detector simulation.

Experiments dedicated to MATiSSe toolbox qualification have been performed successively in the French CEA Saclay OSIRIS reactor, in the Slovenian TRIGA Mark II reactor (Jozef Stefan Institute - JSI) and in the Polish MARIA reactor (National Centre for Nuclear Research - NCBJ) [14, 15]. Various SPNDs (standards and innovative ones) have been tested in systematically and fully characterized locations and confronted to MATiSSe toolbox simulations.

\section{INSTRUMENTATION DESIGN}

The instrumentation proposed in the frame of the DISCOMS project is a specific CEA and THERMOCOAX design. Regarding the relatively low neutron flux conditions, it straightforwardly became mandatory to consider a high thermal neutron sensitivity Rhodium emitter SPND. In addition, Platinum emitter SPND was identified for its mixed response to neutron and gamma irradiations, with rather high gamma sensitivity in favorable conditions. Similar insulation and sheath materials were chosen for the two kinds of SPNDs; alumina and stainless steel 304L (SS304L) due to their common use in nuclear industry and their good behavior under irradiation with time.

Rhodium and Platinum emitter SPNDs show the same cylindrical geometry (see Table 1):

TABLE I. DISCOMS SPND CHARACTERISTICS

\begin{tabular}{ll} 
& DISCOMS SPND \\
\hline Emitter & $\mathrm{Rh}$ or Pt \\
- Diameter & $1 \mathrm{~mm}$ \\
- Length & up to $6 \mathrm{~m}$ \\
Insulator & $\mathrm{Al}_{2} \mathrm{O}_{3}$ \\
- Thickness & $0.45 \mathrm{~mm}$ \\
Sheath & $\mathrm{SS} 304 \mathrm{~L}$ \\
- Outer Diameter & $2.8 \mathrm{~mm}$ \\
- Thickness & $0.45 \mathrm{~mm}$ \\
Cable & $1 \mathrm{AcAc} 10$ \\
\hline
\end{tabular}

The two SPNDs, one thermocouple and a background signal cable are embedded in a tubular envelope including spacers (also called followers) as depicted on Figure 8. The sensitive part can be designed up to 6 meters long while the complete device, called an instrumented 'pole' is ranging from 7 to 30 meters (see Figure 7).

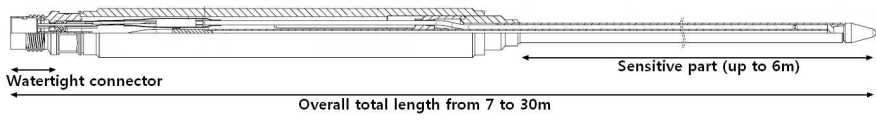

Figure 7: Schematic view of the instrumented DISCOMS pole.

The pole is connected to extension cables (up to 200 meters) using specifically designed and qualified watertight glass-metal connectors [3]. Extension cables are linked to the standalone low current acquisition system placed in a remote location.

\section{INSTRUMENTATION PERFORMANCES}

\section{A. MATiSSe toolbox results}

From the irradiation conditions mentioned in the section II$\mathrm{C}$, the two bare SPND performances were initially calculated for the different configurations. Then, SPNDs are inserted into the DISCOMS pole and their performances are reevaluated. SPND cable influence on delivered currents is also determined by the MATiSSe toolbox. 
All components of the DISCOMS pole and its close environment are then modeled to take into account electrons produced outside SPNDs and possibly depositing their electrical charges in one of the SPND components.

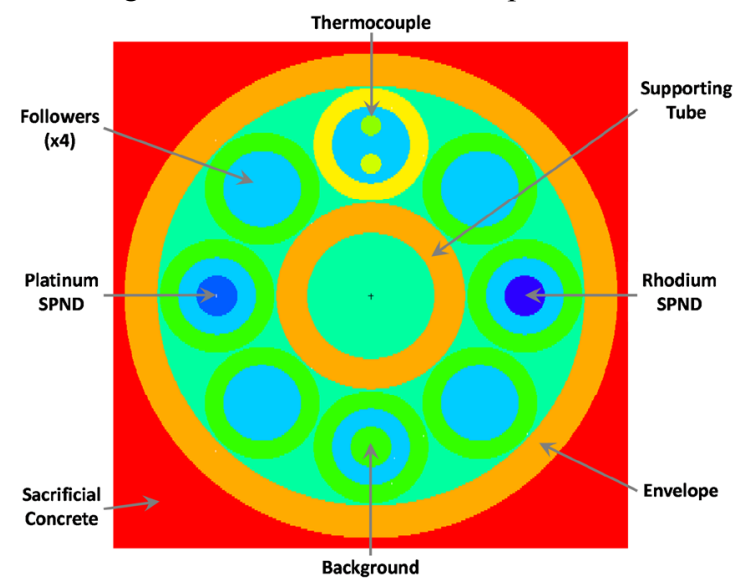

Figure 8: MCNP6 model of the DISCOMS instrumented pole

SPND performances are presented for the GEN2 reactors in 'Normal Operation' (NO) and Severe Accident (SA) when the corium pours on the basemat surface. Two SPND locations are also considered: at reactor core mid height outside the vessel (NO/Seg. 5) and on the concrete basemat surface (NO/Base and SA/Base).

MATiSSe toolbox numerical results are given in Tables II to IV for the Rhodium and the Platinum SPNDs and the Background cable. In these tables, neutron and gamma flux levels are specified for each case using the ' $\Phi_{n}$ ' and ' $\Phi_{g}$ ' columns respectively. The currents given in A. $\mathrm{m}^{-1}$ in the column labeled ' $I(A / m)$ ' represent the final simulation result of the electrical signal delivered by the SPNDs (per unit of emitter length). Such results are directly comparable to the measurement carried out by the operator. Various contributions to the total electric current are expressed as a percentage of the latter.

\section{TABLE II. DISCOMS RHODIUM SPND SIMULATION RESULTS}

\begin{tabular}{lllllll} 
Rhodium & $\Phi_{\mathrm{n}}\left(\mathrm{n} / \mathrm{cm}^{2} / \mathrm{s}\right)$ & $\Phi_{\mathrm{g}}\left(\gamma / \mathrm{cm}^{2} / \mathrm{s}\right)$ & $\mathbf{I}(\mathbf{A} / \mathbf{m})$ & $\left(\mathrm{n}, \beta^{-}\right)$ & $(\mathrm{n}, \gamma)(\gamma, \mathrm{e})$ & $(\gamma, \mathrm{e})$ \\
\hline NO/Seg.5 & $4.26 \mathrm{E}+10$ & $1.45 \mathrm{E}+10$ & $\mathbf{1 . 4 2 E - 0 9}$ & $87.9 \%$ & $10.1 \%$ & $1.9 \%$ \\
NO/Base & $1.34 \mathrm{E}+09$ & $4.44 \mathrm{E}+08$ & $\mathbf{1 . 1 7 E - 1 0}$ & $89.1 \%$ & $10.6 \%$ & $0.3 \%$ \\
SA/Base & $\mathrm{N} / \mathrm{A}$ & $7.27 \mathrm{E}+12$ & $\mathbf{2 . 3 2 E - 0 9}$ & N/A & N/A & $100 \%$
\end{tabular}

TABLE III. Discoms PlatinUm SPND SimULATION RESUlts

\begin{tabular}{lllllll} 
Platinum & $\Phi_{\mathrm{n}}\left(\mathrm{n} / \mathrm{cm}^{2} / \mathrm{s}\right)$ & $\Phi_{\mathrm{g}}\left(\gamma / \mathrm{cm}^{2} / \mathrm{s}\right)$ & $\mathbf{I}(\mathbf{A} / \mathbf{m})$ & $\left(\mathrm{n}, \beta^{-}\right)$ & $(\mathrm{n}, \gamma)(\gamma, \mathrm{e})$ & $(\gamma, \mathrm{e})$ \\
\hline NO/Seg.5 & $4.26 \mathrm{E}+10$ & $1.45 \mathrm{E}+10$ & $\mathbf{4 . 4 5 E}-11$ & $4.6 \%$ & $46.8 \%$ & $48.6 \%$ \\
NO/Base & $1.34 \mathrm{E}+09$ & $4.44 \mathrm{E}+08$ & $\mathbf{2 . 7 5 E - 1 2}$ & $5.3 \%$ & $73.1 \%$ & $21.6 \%$ \\
SA/Base & $\mathrm{N} / \mathrm{A}$ & $7.27 \mathrm{E}+12$ & $\mathbf{1 . 4 2 E - 0 8}$ & N/A & N/A & $100 \%$ \\
\hline
\end{tabular}

Background cable currents result from same level but opposite sign contributions. The resultants are very low and poorly reliable and only given as an indication (see TABLE IV).
TABle IV. Discoms BACKGROUND CABle Simulation Results

\begin{tabular}{lllllll} 
Background & $\Phi_{\mathrm{n}}\left(\mathrm{n} / \mathrm{cm}^{2} / \mathrm{s}\right)$ & $\Phi_{\mathrm{g}}\left(\gamma / \mathrm{cm}^{2} / \mathrm{s}\right)$ & $\mathbf{I}(\mathbf{A} / \mathbf{m})$ & $\left(\mathrm{n}, \beta^{-}\right)$ & $(\mathrm{n}, \gamma)(\gamma, \mathrm{e})$ & $(\gamma, \mathrm{e})$ \\
\hline NO/Seg.5 & $4.26 \mathrm{E}+10$ & $1.45 \mathrm{E}+10$ & $\mathbf{6 . 1 3 E - 1 2}$ & $-10.8 \%$ & $64.2 \%$ & $46.6 \%$ \\
NO/Base & $1.34 \mathrm{E}+09$ & $4.44 \mathrm{E}+08$ & $\mathbf{1 . 6 2 E - 1 3}$ & N/A* & N/A* & N/A* \\
SA/Base & $\mathrm{N} / \mathrm{A}$ & $7.27 \mathrm{E}+12$ & $\mathbf{- 8 . 7 6 E - 1 0}$ & N/A & N/A & $100 \%$
\end{tabular}

\section{B. Discussions}

Figure 9 shows that SPND currents delivered during normal reactor operation remain above the lower current measurement limit $(>1 \mathrm{pA})$. The current levels to be measured are even relatively easy to evaluate with dedicated electronics. The numerical simulations of the instrumented pole developed within the DISCOMS project provide usable signals for all studied configurations. Consequently, MATiSSe toolbox results give DISCOMS partners strong confidence about the use of SPND-based instrumentation for corium monitoring in the event of a severe reactor accident.

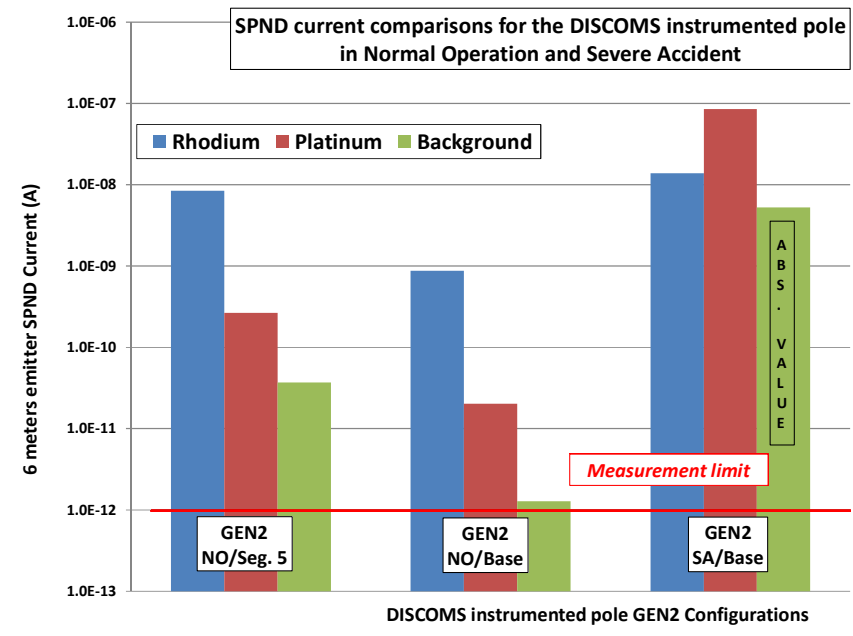

Figure 9: DISCOMS pole SPND current comparisons for Normal Operation and Severe Accident conditions (Negative Background cable SA/Base current is presented in absolute value due to the use of log graphical ordinates).

On-line monitoring and adequate management of SPND current levels in all reactor operation phases should allow the operators to differentiate the reactor conditions: reactor shutdown, normal operation, severe accident without corium migration or severe accident including corium migration towards the concrete basemat.

In addition, the Rhodium and Platinum SPND currents will not evolve the same way at the accident occurrence. Significant current drops following the neutron flux loss and Platinum SPND current large rise during the corium approach will inform the operator about the corium migration towards the concrete basemat.

Calculated Background cable currents are poorly reliable meaning the SPND cable current correction cannot rely on simulations. Hence, correction should be carried out experimentally using a compensation cable. One follower is replaced for this purpose. 
Compensation cable end must coincide with the Rhodium and Platinum emitter end positions. Then compensation cable current has to be subtracted from the Rhodium and Platinum SPND measured currents.

\section{CONCLUSION}

In the framework of the ANR DISCOMS project, the feasibility of a remote corium migration monitoring in the unlikely event of a severe nuclear accident is considered and simulated. The corium progression is monitored by means of an instrumented pole equipped with SPNDs and a Thermocouple.

CEA laboratories and the THERMOCOAX SAS Company have designed an instrumented pole according to the considered implementation and irradiation conditions. These conditions for GEN2 reactors have been estimated by DISCOMS partners (IRSN and CEA/SERMA).

A Rhodium and a Platinum emitter SPNDs are encapsulated in this instrumented pole. Their performances have been calculated using the LDCI numerical tool called 'MATiSSe' for different SPND locations.

MATiSSe toolbox simulation results provide SPND currents that demonstrate the proposed instrumented pole capabilities. Its adequate positioning is on the reactor vessel side and on the reactor concrete basemat. These configurations would allow to monitor the corium progression towards the concrete basemat in case of a severe nuclear accident. Coupled temperature measurement would also provide additional information on corium migration.

The full monitoring equipment is planned to be tested during a joined CEA-THERMOCOAX experimental campaign in some realistic irradiation conditions in the Slovenian TRIGA Mark II reactor (Ljubljana, JSI, pool type research reactor $250 \mathrm{~kW}$ [16]) during fall 2017. Experiments will be supported by specific neutron and gamma flux and spectra calculations in the instrumented pole irradiation locations (taking into account actual irradiation geometry and materials). Additional measurements will be performed for thermal and fast neutron flux level (with activation dosimetry) and gamma flux level (with miniature ionization chamber [17]) purposes.

\section{ACKNOWLEDGMENT}

This project is co-funded by the French Programme d'Investissements d'Avenir (PIA) and managed by the French National Research Agency (ANR).

\section{REFERENCES}

[1] P. Ferdinand et al., 'DISCOMS: DIstributed Sensing for COrium Monitoring and Safety', CANSMART Conf. 2015, 15-17 July 2015, Vancouver, Canada.

[2] J.W. Hilborn, 'Self-powered neutron detectors for reactor flux monitoring', Nucleonics, vol. 22, no 2, pp 69-74, 1964.

[3] THERMOCOAX industrial references $\mathrm{n}^{\circ} 304803$ and 304807.

[4] X-5 Monte Carlo Team, MCNP6 User's Manual, Version 1.0, May 2013, LA-CP-13-00634.
[5] TRIPOLI-4 Monte Carlo Transport Code, http://www.nea.fr/abs/html/nea-1716.html (2013).

[6] J. Kopecky, 'Final verification and validation of JEFF-3.2', NEA document, JEF/DOC-1590, April 2015.

[7] National Nuclear Data Center, Brookhaven National Laboratory. ENDF6 Formats Manual. Data Formats and Procedures for the Evaluated Nuclear Data File ENDF/B-VI and ENDF/B-VII. CSEWG Document ENDF-102, Report BNL-90365-2009.

[8] M. Brovchenko et al., 'Neutron-gamma flux and dose calculations in a Pressurized Water Reactor (PWR)', Joint Conf. on Radiation Shielding (ICRS-13) \& $19^{\text {th }}$ Topical Meeting of the Radiation Protection \& Shielding Division of the American Nuclear Society (RPSD-2016), 3-6 October 2016, Paris, France.

[9] L. Vermeeren, R. Van Nieuwenhove, 'Theoretical study of radiation induced electromotive force effects on mineral insulated cables', American Institute of Physics, Review of Scientific Instruments, vol. 74 no 11,2003

[10] L. Vermeeren, H. Carcreff, L. Barbot, V. Cloute-Cazalaa, S. Fourrez and L. Pichon, 'Irradiation tests of prototype self-powered gamma and neutron detectors', $2^{\text {nd }}$ ANIMMA Intern. Conf. publication DOI 10.1109/ANIMMA.2011.6172889.

[11] G.F. Lynch, 'Some theoretical aspects of self-powered detectors', Atomic Energy of Canada Limited, Rapport AECL-5124 paper 1.8, 1974.

[12] C. Blandin, 'Contribution au développement de collectrons pour la mesure instantanée et sélective des différents champs de rayonnements en réacteurs nucléaires', Thèse de l'Institut National Polytechnique de Grenoble, France, 1998.

[13] JANIS4.0 web nuclear data library available at http://www.oecd-nea.org/janis/

[14] L. Barbot et al., 'Calculation to experiment comparison of SPND signals in various nuclear reactor environments', 4th Intern. Conf. ANIMMA 2015, 20-24 April 2015, Lisbon, Portugal.

[15] L. Barbot et al., 'Experimental validation of a Monte Carlo based toolbox for Self-powered neutron and gamma detector simulation in the OSIRIS MTR', PHYSOR Conf. 2016, 1-5 May 2016, Sun Valley, USA.

[16] B. Smodis and L. Snoj, "Utilization and Application of the Slovenian TRIGA Reactor," "Jo zef Stefan" Institute, Ljubljana, Slovenia, Tech. Rep., 2011. [Online]. Available: http://wwwpub.iaea.org/MTCD/Publications/PDF/ P1575 CD web/datasets/papers/ A29n\%20Smodis.pdf.

[17] D. Fourmentel et al., 'Measurement of photon flux with a miniature gas ionization chamber in a Material Testing Reactor', Nuclear Instruments and Methods in Physics Research Section A, vol 724, pp. 76-82, 2013. 